\title{
THE ROLE OF TALENT MANAGEMENT IN IMPROVING STRATEGIC PERFORMANCE OF SAUDI MANUFACTURING COMPANIES
}

\author{
Feryal Abdullah Abdulrahman Al-Oumi ${ }^{1}$, Dr. Majed Al Doubi ${ }^{2}$ \\ ${ }^{1,2}$ Faculty of Business and Management, Al Medina International University, Kuala Lumpur, \\ Malaysia
}

Article DOI: $\underline{\text { https://doi.org/10.36713/epra8423 }}$ DOI No: 10.36713/epra8423

\begin{abstract}
This paper aimed at investigating the impact of talent management strategies on improving the strategic performance of business organizations. To achieve the study objectives, a survey methodology was utilized using questionnaires for collecting data from seventy-six Saudi manufacturing listed companies which represents the research population. Statistical Package for Social Sciences (SPSS, V. 19) was utilized for data analysis using several statistical tests and methods including arithmetic Mean, Standard Deviation, Exploratory Factor Analysis, and Linear and step Regression.

The main findings of the study indicate that talent management strategies dimensions together have a significant impact on strategic performance. However, individually, it was found that development and motivation were the only talent strategy dimensions that have a significant impact on strategic performance. In addition, the study reveals that talent management strategies were moderately implemented in Saudi manufacturing companies with a mean of (3.57) and that their strategic performance was also moderate with a mean (3.55).

The study presented several recommendations for Saudi manufacturing companies including that importance of establishing specific section for talent management responsible for implementing talent management strategies according to scientific methodology that would enable these companies to achieve positive results in the long run.

KEYWORDS: Talent management, Strategies performance, Manufacturing Companies.
\end{abstract}

\section{INTRODUCTION}

Business organizations are experiencing many challenges on the list of technological, economic, political, social and other levels that have had a significant impact on business organization strategies in order to come up with solutions that will bring about the development of organizations to meet those challenges and achieve an ongoing competitive advantage, and many of these organizations have felt the importance of focusing on the human element, which can be a key focus and support for them to help them survive, continue and excel. Business organizations need outstanding talent that leads the stage of change and development and are competitive, so talent management is one of the biggest challenges they face, and in preparation for the prospects for improved growth levels in business organizations in the wake of the global economic crisis, most of them plan to make changes to their talent management programs. It must also make extraordinary efforts to build an effective and efficient talent strategy by relying not only on attracting and retaining talent, as it plays a major role in improving business performance and increasing productivity.

Given the role that human resources talent and management play in organizations, it is important to identify and analyses them at the organization level in the Arab countries, specifically in Saudi Arabia, and the importance of focusing on talent management to improve the strategic performance of these organizations, which this study seeks to focus on.

\section{STUDY PROBLEM}

Improving the strategic performance of business organizations is currently the main focus of their attention due to the increasing competition between 
organizations at the local and global levels, which has generated a different vision for organizations and made their vision of achieving the best performance now and seeking the best in the future, and making them keen to adopt new visions and concepts within the framework of human resources and focus on the human element, especially talent and investment for their own benefit, and business organizations believe that the application of their talent management strategies will achieve the desired superiority and competitive advantage in view of others of organizations. However, despite the broad attention that talent management has gained since the 1990s, some organizations have had difficulty implementing talent management programs [1], and the concern is that talent management is just a concept--not something organizations strive internally enforce[2], and in the Arab Gulf Cooperative Council there is limited research on talent management, also in Saudi Arabia there is a lack of empirical studies showing the relationship between talent management strategies and organizational change [1]. The problem with the study is therefore to answer the following question: Do talent management strategies play a role in improving strategic performance in business organizations?

\subsection{Study questions:}

The study sought to answer the following questions: What are the concepts of talent management and strategic performance? What is the level of application of talent management strategies in Saudi industrial companies contributing from the point of view of their managers? What is the level of strategic performance in Saudi industrial companies contributing from the point of view of their managers?

What is the impact of the application of talent management strategies on strategic performance in Saudi industrial companies contributing from the point of view of their managers?

\subsection{Study objectives:}

The study aims to identify the role of talent management strategies in improving the strategic performance of Saudi industrial business organizations contributing. The study also seeks to achieve the following objectives: Rooting the concepts of talent management and strategic performance. Learn about the level of application of talent management strategies from the point of view of managers in Saudi industrial joint stock companies. Learn about the level of strategic performance from the point of view of managers in Saudi industrial joint stock companies. Learn about the impact of talent management strategies on strategic performance from the point of view of managers in Saudi industrial joint stock companies.
Make a range of recommendations and proposals that will improve strategic performance in Saudi industrial companies by applying talent management strategies.

\subsection{The importance of the study:}

The importance of the study lies in trying to examine the role played by talent management strategies in improving the strategic performance of Saudi industrial companies contributing from the point of view of their managers and the importance of the study comes through the following: The rooting of two modern concepts of talent management and strategic performance, which have recently increased interest in them at the theoretical and applied levels in the light of the increasing intensity of competition in business organizations and the role that the human component can play as an intangible resource in improving the performance and quality of business organizations' services. The importance of the considered category represented in the senior management of Saudi industrial joint stock companies. The researcher hopes that this study will provide business organizations and stakeholders with information on the relationship between the study variables and the importance of practicing and applying talent management strategies in order to improve strategic performance, thus potentially being an important reference for researchers and practitioners in talent management and strategic performance. As far as the researcher is aware, this study is one of the first to address talent management strategies as a tool that organizations may use to improve their strategic performance in business organizations in general and Saudi Arabia in particular. It needs talented skills to facilitate implementation across different management departments, and the real challenge for organizations is to keep talented staff. Hence, talent management is critical to the long-term success of any organization. [3] Talent management is a continuous process that plans talent needs, attracts the very best talent, speeds time to productivity, keepings the highest performers, and enables talent mobility across the organization. There must be a match between capabilities and needs to balance the notion of talent supply with business demand.[4] The presence of talent gives organizations a competitive advantage, which is unique to other organizations, which requires encouragement to work creatively to improve performance at all levels. Therefore, the appreciation and value of talent are linked to individuals' work provided that they are unique, essential, and affect the achievement of goals. 


\subsection{Study model}

Figure (1) below shows the study model:

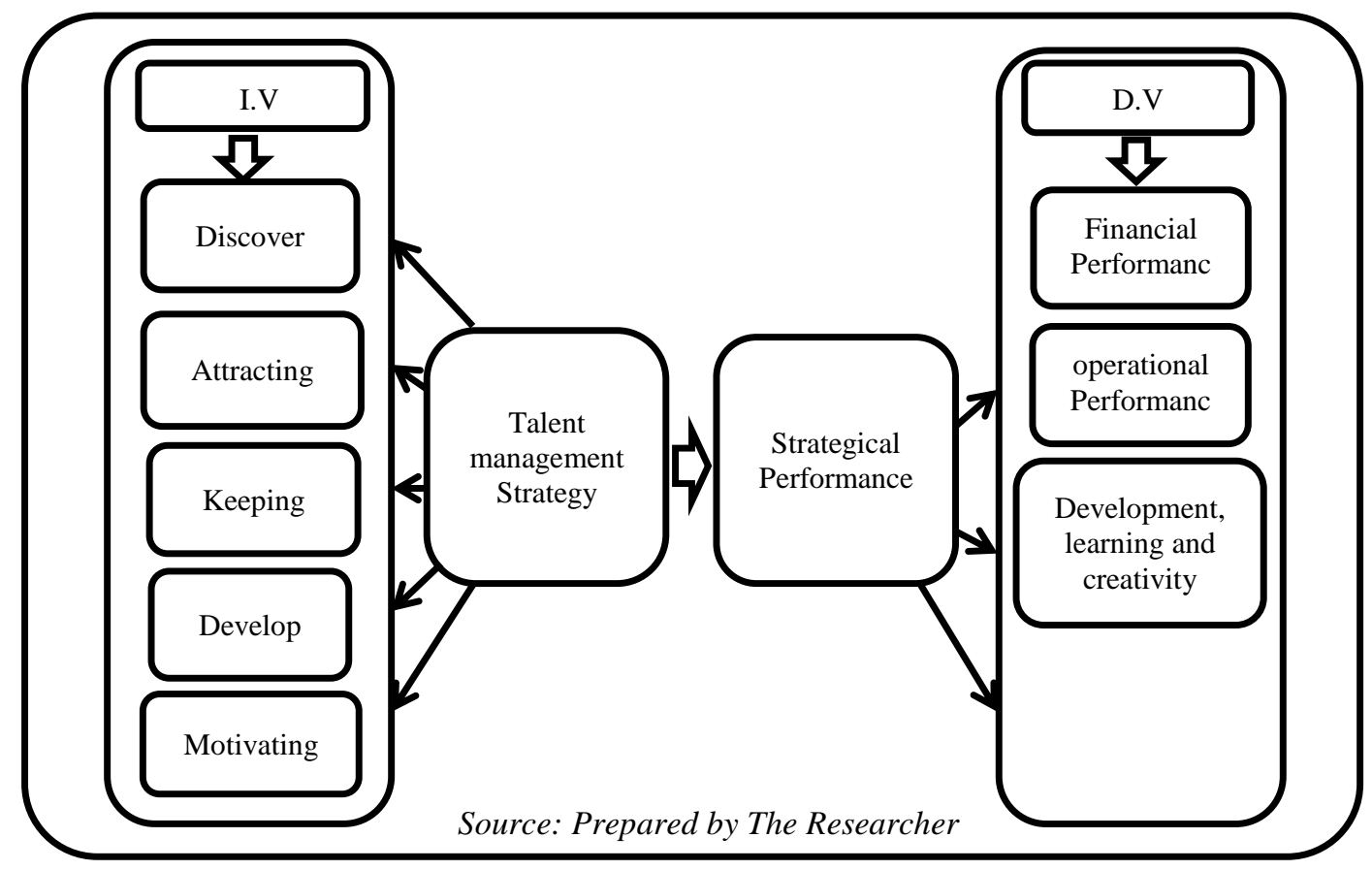

1.6 Procedural definitions of study variables:

Talent management: It is challenging to define the concept of talent management, and it is an ambiguous concept. There is no clear definition for it [5], [6]Blass asserts that because of the differing visions of researchers for this department, each has different visions of which some might be rigid. A third team is a part of the performance management system, and a fourth team considers it a strategy. [6] One of the latest methods of human resources management and the latest development and change strategies in business organizations is defined as activating the role of talent in the organization and working to select, attract, discover and retain it by stimulating and developing it.

Talent management strategies: It is a set of strategies and ways in which the goal of talent management is achieved, such as talent discovery strategy, talent attraction strategy, talent development strategy and talent Motivating strategy, which will be measured through a range of questions identified in the study questionnaire.

Strategic performance: The set of results of the organization's practices and activities, which are expected to meet the planned and established objectives. [7] was said to reflect the organization's ability and ability to achieve its objectives, and reflect how material, human and financial resources are used appropriately for their purpose. [8]
It is a set of results from the organization's activities and practices that are expected to meet the planned and set objectives, include output-oriented performance indicators and include operational and financial performance, and competitive performance, an act that all parties in the organization seek to promote.

\section{7 hypotheses of the study:}

The discovery of the first and main important talents of human resources departments in carrying out their basic functions of polarization and selection of workers and training so that it takes into account accuracy and discovery of talent and work to refine and maintain it. [9]

Unfortunately, many organizations in the Arab world lack a culture of interest in talent, where the management of human resources is focused on measuring the gap in performance, and working on to address it through training, development, mentoring and motivation programs because the continuation of this gap represents a threat to targeted performance and although talent management needs less effort and cost to achieve excellence and success than threat management, many contemporary organizations in the Arab world focus on threat management in the organization and ignore talent management, and the difference between threat management and opportunities in this regard is that threat management is 
concerned with seeking to achieve an acceptable level of performance by focusing on focusing on threat management in the organization. On treatment while talent management aims to achieve excellence and creativity in managing opportunities by supporting and developing talent management. [10]

In another study, the researcher said, "There is some lack of research into organizations' actual practices and how talent management activities are created". [6], [10] The theories of the study can therefore be developed by knowing the impact of talent management strategies on the strategic performance of business organizations and any dimensions or strategic performance indicators most affected by these strategies. The study therefore aimed to examine the following main hypothesis: There is no statistically significant impact at the level of significance $(0.05 \geq \alpha)$ of talent management strategies (Ddiscovering, Attracting, Keeping, Developing, Motivating) in its community or individually in improving strategic performance with its indicators (financial performance index, operational performance index, development, learning and creativity index, customer index) combined from the point of view of managers in Saudi industrial joint stock companies.

Four sub-hypotheses also emerge from this hypothesis: There is no significant statistically significant impact at the level of significance $(0.05 \geq \alpha)$ of talent management strategies (Ddiscovering, Attracting, Keeping, Developing, Motivating) in the financial performance index as one of the indicators of measuring strategic performance from the point of view of managers in Saudi industrial joint stock companies. There is no significant statistically significant impact at the level of significance $(0.05 \geq \alpha)$ of talent management strategies (Ddiscovering, Attracting, Keeping, Developing, Motivating) in the operational performance index as one of the indicators of strategic performance measurement from the point of view of managers in Saudi industrial joint stock companies. There is no significant statistically significant impact at the level of significance $(0.05 \geq \alpha)$ of talent management strategies (Ddiscovering, Attracting, Keeping, Developing, Motivating) in the development, learning and creativity index as one of the indicators of measuring strategic performance from the point of view of managers in Saudi industrial joint stock companies. There is no significant statistically significant impact at the level of significance $(0.05 \geq \alpha)$ of talent management strategies (Ddiscovering, Attracting, Keeping, Developing, Motivating) in the customer index as one of the indicators of strategic performance measurement from the point of view of managers in Saudi industrial joint stock companies.

\subsection{Statistical treatment}

To answer the study's questions and test its hypotheses, descriptive and analytical statistics methods were used, using statistical package for social sciences, and to answer the study questions, mathematical averages and standard deviations were used for all dimensions of the independent and successive study, and a multi-step and gradual line regression analysis to ensure that the model was fit to test the two-study hypothesis and to see which independent variables had a more significant impact on the variable in this study. Therefore, the values of the calculation averages reached by the study will be treated as follows: High (3.6 and above), medium (3.59-2.79) low (2.78 and less), Accordingly, if the average value of paragraphs is greater than (3.6), the level of perceptions of the respondents is high, which means that the sample members agree to the paragraphs, but if the average value of the calculation (3.59-2.79) is average, and if the calculation average is less than (2.79) the level of perceptions is low.

\section{Findings and recommendations}

After performing the complete statistical operations, the results were as follows:

The study examined the impact of talent management strategies in strategic performance indicators in Saudi industrial companies contributing to the following are the most important findings of the study:

1. The results indicate that the overall arithmetic average of the responses of the complete talent management strategies was averaged (3.57) and this demonstrates the need for Saudi industrial companies to contribute to the strategies of talent management more care and attention in order to keep up with the progress and global competition, and the availability of these strategies according to the responses of the respondents as follows: strategies (Ddiscovering, Attracting, Keeping, Developing, Motivating) were medium. This result, based on the questionnaire paragraphs, demonstrates that the senior management of the industrial joint stock companies is well oriented towards discovering and attracting talent, indicating

2. That they understand the importance of focusing on the human element, which is a major supporter of them and helps them to survive and continue, and this is consistent with the strategic objective of these companies to achieve excellence and development so that they can excel in the local and global competitive markets.

3. The results show that the total arithmetic average level of availability of strategic performance 
4. indicators in Saudi industrial joint stock companies was average at (3.55) and the operational performance index came in first place with an average calculation of (3.92), followed by the customer index and then the financial performance index and finally the learning and creativity index. The occupation of the operational performance and customer indicators advanced among the averages is evidence of the interest of Saudi industrial companies in recruiting highly skilled and distinguished human resources capable of managing operational operations efficiently and at an advanced level, which reflected on operational performance in general, and this was agreed with the study. [11] Where the study found a moral correlation between the elements of operations strategy and areas of strategic performance, which confirms

5. the orientation of the attention of major companies to the operational performance of its great association with strategic performance and from there. The strategic performance of business organizations can be measured.

6. The results show that there is an impact of the application of talent management strategies combined on strategic performance indicators in Saudi industrial joint stock companies, but this effect was strong for the talent Motivating index with a statistical significance of less than (05.05).

To achieve any more influential factors, the results after the gradient regression test showed that the talent development strategy was at its highest level, followed by a talent Motivating strategy of 050,000, respectively.

This is in line with what most literature has emphasized that the development of staff, especially talented people, is an important way to improve institutional performance in general and thus the strategic performance of organizations, developing talent first and motivating them to enable the Keeping of talented cadres within organizations and achieve excellence within and outside organizations, in addition to enabling organizations to implement new strategies at work that increase the efficiency of organizations' performance and development, This is consistent with a study, [12] that found that large companies implement a range of training programs within on-the-job training, that they reward their talented people with physical and moral motivation, that they consider them talented, and that there are contributing factors in staff Keeping, such as support for job development.
The impact of other strategies on strategic performance has been weakened because the talent development and motivation strategies will undoubtedly lead to the presence of other strategies because of the socio-economic conditions that lead the individual to look for business organizations that offer a greater advantage and development of their capabilities and because they drive and encourage staff in general to perform best for the organization to achieve a high and sustainable competitive advantage.

\section{CONCLUSION}

In the light of the results of the study, the study proposes a number of recommendations: Business organizations need to pay more attention to providing talent management or allocating a human resources job to discover and take care of their talents. As Rostam study Many organizations face high attrition of employees; they lose their top talent because of management's negligence towards employees' talent. It is essential to keeping top talent by an effective talent management system implementing in the organization, [4] Applying talent management according to a codified scientific method enables business organizations to achieve positive results in the long run. Try to share experiences on talent management by joining local and international associations interested in this matter.

Follow up on published scientific research on talent management and the experiences of modern organizations on their application. Hold annual conferences to keep up with the latest talent management and implement its recommendations first and foremost. Spreading talent management concepts as an important tool for improving strategic performance and focusing on the need to seek best practices by:

Enable talent to participate and make strategic decisions for the company. Enable the company's talents to choose the advantages of motivating and supporting them in multiple and specific choices at the same time in order to raise their morale and achieve psychological stability for them. Develop strategic plans to provide, maintain and invest talented talent as a competitive advantage.

\section{REFERENCES}

1. Bafagih, L. (2019). Developing Talent Pipelines for Small and Medium-Sized Enterprises in Saudi Arabia. Walden University, College of Management and Technology.

2. Ekelöf, S., Holmström, C., \& Lindberg, N. (2019). Talent within Strategic Human Resource Management (Dissertation). Retrieved from 
http://urn.kb.se/resolve?urn=urn:nbn:se:Inu:diva-

85384.

3. Sukanya, M, (2011)," Talent management strategies and challenges in the competitive era: a study of select software \& BPO companies in India " Jawaharlal Nehru Technological University.

4. Rostam, F. (2019). A Review of Talent Management as a Key in any Organizations. The International Journal of Indian Psychology. 7. 78-83.

5. Adebola, Sunday (2017) Talent Management: Perspectives, Practices, and Evaluation in UK Private Sector Organizations. Doctoral thesis, University of Huddersfield. http://eprints.hud.ac.uk/id/eprint/34166.

6. Saleh, Ahmed Ali and Saad, Ali Mowat (1431), "Talent Management: Scientific and Strategic Perspective", Institute of Public Administration Management Magazine, Oman, Issue 120.

7. Gitonga, A. (2019), Influence of Human Resource Capability in Relating Talent Management Strategy and Competitive Advantage, Journal of Human Resource Management.Vol.7, No. 4, 2019, pp.120130.doi:10.11648/j. jhrm. 20190704.16.

8. Rami Tarakji (2010) "How do the best employers in Kuwait understand and apply Talent Management?" A thesis submitted in partial fulfillment of the requirements for the degree of Masters of Business Administration (MBA) of the Maastricht School of Management (MSM), Maastricht, the Netherlands. 